\title{
THE DEMONSTRATION AND SIGNIFICANCE OF SYNERGISM BETWEEN $\beta$-LACTAM ANTIBIOTICS
}

\author{
J. M. T. Hamilton-MilleR* \\ Sir William Dunn School of Pathology, Oxford
}

Plate XIV

SYNERGISM between selected pairs of $\beta$-lactam antibiotics, recognised since 1964 (Hamilton-Miller, Smith and Knox, 1964; Sabath and Abraham, 1964; Sutherland and Batchelor, 1964) depends upon the competitive inhibition of $\beta$-lactamase, and seems to be the only example of antibacterial synergism explainable in precise molecular terms (see Jawetz, 1968). The purpose of the experiments described here was twofold: firstly, they were designed to develop a means whereby synergism could be demonstrated unequivocally, with ease and in such a way that some analysis of the results would be possible. Secondly, they were used to test whether combinations of $\beta$-lactam antibiotics are likely to show a significant advantage over similar drugs used singly, when the compounds are present in concentrations that exist in body fluids during therapy.

\section{MATERIALS AND METHODS}

Penicillins and cephalosporins. Sodium benzylpenicillin, cephaloridine, cephalothin and potassium cephalosporin $\mathrm{C}$ were obtained from Glaxo Research Laboratories, Greenford. Phenoxymethylpenicillin (penicillin V) from Distillers Co. (Biochemicals), Speke, was converted into the potassium salt by reaction with potassium 2-ethylhexanoate in butanol. Phenethicillin, propicillin, carbenicillin, sodium ampicillin, cloxacillin, oxacillin, and dicloxacillin were obtained from Beecham Research Laboratories, Betchworth, Surrey; quinacillin from Boots Pure Drug Co., Beeston; cephaloglycin and cephalexin from Eli Lilly \& Co., Indianapolis. The sodium penicillin $\mathrm{N}$ sample used (Abraham, Newton and Hale, 1954) was 25 per cent. pure. N-benzoyl cephalosporin C, N-benzoyl penicillin $\mathbf{N}$ and cephaloram were prepared as previously described (Newton and Abraham, 1954; Abraham and Newton, 1956; Loder, Newton and Abraham, 1961).

Bacterial strains. The following Gram-negative strains were used: Pseudomonas aeruginosa NCTC 8203 (Sabath, Jago and Abraham, 1965); Klebsiella aerogenes strains 366, 373 and 402 (Smith and Hamilton-Miller, 1963); Escherichia coli strains 214T (Smith, 1963), 419 (Smith and Hamilton-Miller), K12/TEM and K12/7268 (the two K12 strains carry R factors-Datta and Kontomichalou, 1965; R7268 has been renamed R1 by Meynell and Datta, 1966); Proteus morgani strains G and 185 and Proteus rettgeri 410 (Smith and Hamilton-Miller); Proteus vulgaris strains $\mathrm{M}$ and $\mathrm{J}$ and Proteus mirabilis 1 and 6 (kindly given by Miss Pamela Waterworth); Enterobacter cloacae strains P99 and 256 (Hennessey, 1967). Staphylococcus aureus E3 (Knox, 1960) was the only Gram-positive strain used. These organisms were chosen because of their great resistance to penicillins and their ability to produce, collectively, a wide variety of representative $\beta$-lactamases.

Received 16 June 1970; accepted 3 Nov. 1970.

* Present address: Mycology Dept, Charing Cross Hospital Medical School, 53 Aspenlea Road, London, W.6.

J. MED. MICROBIOL.-VOL. 4 (1971) 
Ps. aeruginosa 8203, K. aerogenes 402, E. coli 419 and K12/7268, and Staph. aureus E3 were used in the experiments designed to demonstrate synergism; the remainder of the strains, plus $P s$. aeruginosa 8203, were used in experiments to assess the significance of synergism.

\section{Demonstration of synergism}

Preparation of plates. Organisms were grown overnight at $37^{\circ} \mathrm{C}$ in Oxoid brain-heart infusion (BHI) broth; such cultures contained about $10^{9} \mathrm{Gram}$-negative bacteria per $\mathrm{ml}$, or about half this number of Staph. aureus E3. Pour-plates were made using a 2 per cent. $(\mathrm{v} / \mathrm{v})$ inoculum of an overnight culture in $\mathrm{BHI}$ agar; they were stored at $4^{\circ} \mathrm{C}$ for no more than 5 days. Plugs of agar were removed with a sterile cork-borer of $8.5 \mathrm{~mm}$ diameter, giving the pattern of wells shown in fig. 1; the separation of the top pair of wells (known here as the " adjacent" wells) was $5 \mathrm{~mm}$, that of the bottom pair $30 \mathrm{~mm}$. The two left-hand wells were filled $(0.25 \mathrm{ml})$ with a solution of one drug, and the right-hand wells with a solution of another, Plates were incubated at $37^{\circ} \mathrm{C}$ overnight. These plates will be referred to as " paired-hole" plates.

Reading of plates. This was facilitated by the fact that only subinhibitory concentrations of the drugs were used, so that any zone of inhibition was the result of synergism. This was considered to have occurred if there was a zone between the adjacent wells but none around the other wells (as in fig. 1). Areas of the zones-a measure of the degree of synergism-were assessed by tracing their outlines on to stiff card, cutting this out and weighing.

Design of experiments. The " maximum non-inhibitory concentration" (MNIC) for each compound to be tested was first determined by assaying appropriate concentrations by the hole-plate method (Brownlee et al., 1948); MNIC was obtained by extrapolation from a plot of zone diameter against log. antibiotic concentration. In most experiments Ps. aeruginosa 8203 was used and the rationale described below for this strain was also applied to the other strains used, taking advantage of previously gained knowledge of certain properties of their $\beta$-lactamases (Hamilton-Miller, Smith and Knox, 1964, 1965; HamiltonMiller, 1967, 1968, 1970; Smith, Hamilton-Miller and Knox, 1969). Compounds were tested for their ability to act as the " protected" and the "protecting " member of synergistic pairs, against Ps. aeruginosa 8203, by testing at their MNIC (or at $20 \mathrm{mg}$ per ml, if MNIC was greater than this) with cloxacillin $(20 \mathrm{mg}$ per $\mathrm{ml})$ and with cephaloridine ( $20 \mathrm{mg}$ per $\mathrm{ml}$ ), respectively. These two compounds were chosen on the basis of the findings of Sabath et al. (1965) that cloxacillin, a highly efficient competitive inhibitor of Ps. aeruginosa $\beta$-lactamase, is capable of preventing almost totally the enzymic destruction of a hydrolysable compound, and that cephaloridine is readily protected from hydrolysis by virtue of its comparatively low affinity for the enzyme.

Analysis of synergism. Isobolograms were constructed from the results of minimum inhibitory concentration (MIC) tests (see below); this type of plot, in which the inhibitory power of various combinations of two antibiotics is expressed graphically (see fig. 3), is a very convenient method for the analysis of suspected synergism (see Sabath, 1968). An additive effect is shown by a straight-line plot, an antagonistic effect by a convex plot, and a synergistic effect by a concave plot. It should be noted that this interpretation is valid only if arithmetic scales are used; logarithmic scales complicate this analysis, and should be avoided.

MICs of antibiotics, either alone or in combination with another antibiotic, were determined by either the tube or the plate serial doubling-dilution technique. In the former method, $50 \mu$ l of overnight BHI broth culture was inoculated into tubes containing $1 \mathrm{ml}$ amounts of BHI and the mixtures were read for bacterial growth after overnight incubation at $37^{\circ} \mathrm{C}$. In the plate method, various amounts of antibiotic(s) were added to discrete volumes of melted BHI agar containing $25 \mu \mathrm{g}$ per $\mathrm{ml}$ 2,3,5-triphenyltetrazolium chloride, which were poured into petri dishes of $5-\mathrm{cm}$ diameter. The surface of the solidified agar was spread with $0.1 \mathrm{ml}$ of an overnight culture, and the plates were read after overnight incubation. 
Bactericidal activity was investigated in the case of cephaloridine $(40 \mathrm{mg}$ per $\mathrm{ml})$ and dicloxacillin $(20 \mathrm{mg}$ per $\mathrm{ml}$ ) acting against $P$ s. aeruginosa 8203 . From the zone on this plate (see fig. 2) two plugs of agar were removed with a sterile cork-borer of 5-mm diameter; each plug (volume $=60 \mu \mathrm{l}$ ) was extruded under aseptic conditions into a separate $10-\mathrm{ml}$ sample of BHI broth, and these bottles, together with appropriate controls, were incubated overnight. The controls were as follows: (1) duplicate plugs taken from unused pourplates, each incubated in $10 \mathrm{ml}$ BHI broth and (2) similar plugs each incubated in $10 \mathrm{ml}$ BHI broth that contained $240 \mu \mathrm{g}$ cephalorine $+120 \mu \mathrm{g}$ dicloxacillin per $\mathrm{ml}$. These concentrations were higher than could possibly have been contributed to the broth by diffusion from the test plug.

\section{Screening tests}

Antibiotic combinations were tested in paired-hole plates using the following potentially synergistic pairs: methicillin/cephaloridine, methicillin/cephalexin, methicillin/ampicillin, cloxacillin/cephaloridine, cloxacillin/cephalexin, and cloxacillin/ampicillin. The drugs were each used at a concentration of $1 \mathrm{mg}$ per $\mathrm{ml}$ (representing levels that can be attained in the urine), in combination and alone. Screening was also carried out at the $20 \mu \mathrm{g}$ per $\mathrm{ml}$ level (representing concentrations that can be attained in the blood), by making up every combination as a single solution (e.g., cephaloridine was dissolved at $20 \mu \mathrm{g}$ per ml in a $20 \mu \mathrm{g}$ per $\mathrm{ml}$ solution of methicillin), and assaying each in a separate well by the conventional hole-plate assay.

In cases where a single compound gave a zone of inhibition, the area $\left(A_{1}\right)$ of this zone was measured and subtracted from the area $\left(\mathrm{A}_{2}\right)$ of the zone observed when the compound was used as a member of a combination; if $A_{2}-A_{1}>10 \mathrm{~mm}^{2}$, it was taken that synergism had occurred.

\section{RESULTS}

\section{Demonstration and analysis of synergism}

Ps. aeruginosa. The following compounds were used against this strain: benzylpenicillin, phenoxymethylpenicillin, phenethicillin, propicillin, ampicillin, carbenicillin, methicillin, penicillin $\mathrm{N}$, N-benzoyl penicillin $\mathrm{N}$, cloxacillin, dicloxacillin, and quinacillin; cephalosporin $\mathrm{C}$, N-benzoyl cephalosporin $\mathrm{C}$, cephalothin, cephaloridine, cephaloglycin, and cephalexin.

The only compounds that acted synergistically with $20 \mathrm{mg}$ per $\mathrm{ml}$ of cephaloridine at or below their respective MNICs were methicillin (1 mg per $\mathrm{ml}$ ), cloxacillin and dicloxacillin (each at $20 \mathrm{mg}$ per $\mathrm{ml}$ ); thus, only these three penicillins can act as the "protecting" member of a synergistic pair.

Of the penicillins listed above, only benzylpenicillin, phenoxymethylpenicillin, ampicillin, and penicillin $\mathrm{N}$ acted synergistically with cloxacillin. With the first three compounds, levels down to one-eighth of the MNIC continued to show synergism with $20 \mathrm{mg}$ per $\mathrm{ml}$ of cloxacillin. Cephalothin, cephaloridine (each at $20 \mathrm{mg}$ per $\mathrm{ml}$ ) and cephalosporin $\mathrm{C}(7 \mathrm{mg}$ per $\mathrm{ml}$ ) showed marked synergistic activity when tested with cloxacillin. With the cephaloridine/cloxacillin combination, the concentration of each component could be reduced 16-fold without the effect being lost. The other cephalosporins failed to show synergism when tested with cloxacillin.

In the bactericidal test, the control bottles all grew Ps. aeruginosa plentifully after overnight incubation, whilst the two test bottles failed to grow. Thus, the plugs cut from the zone of inhibition must have been sterile before they were added to the broth, since the second control proved that the amounts of each 
antibiotic carried over in the plug would not have prevented growth. The combined effect of the two antibiotics was therefore bactericidal.

The isobologram constructed from the results of the MIC tests using cephalosporin $\mathrm{C}$ and cloxacillin (fig. 3) indicates a high degree of synergy (experimental plot extremely concave).

K. aerogenes 402. Ampicillin, carbenicillin and cephaloridine were tested as " protected" compounds using methicillin and quinacillin as "protecting"

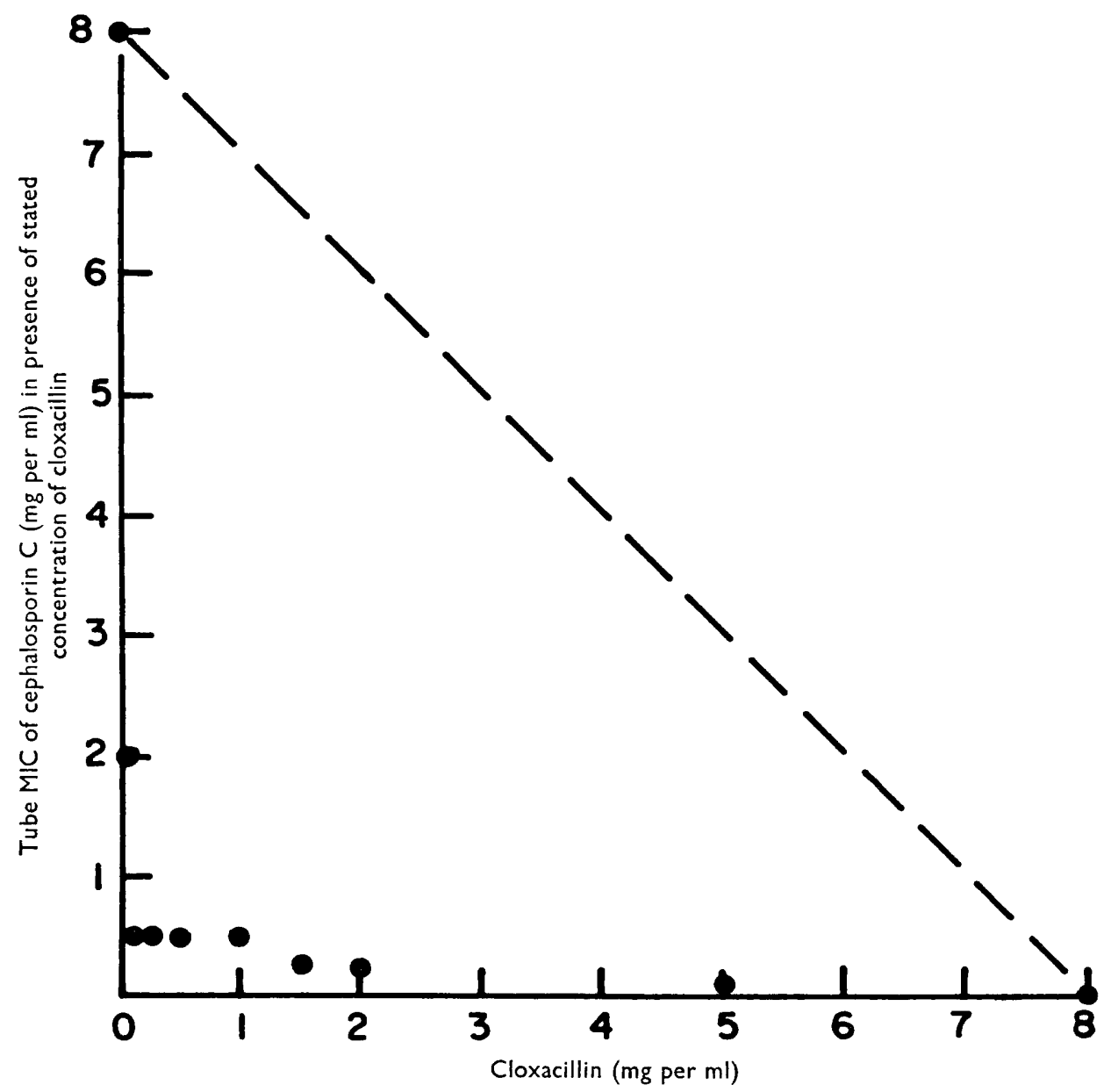

FIG. 3.-Isobologram for combined action of cloxacillin and cephalosporin $\mathrm{C}$ on Ps. aeruginosa NCTC 8203. Each point represents the tube MIC for cephalosporin $C$ determined in the presence of a different amount of cloxacillin. These points would fall along the pecked line if the combination were merely additive.

compounds, each compound being at MNIC. Of the six combinations tested, two showed synergism-ampicillin/methicillin and cephaloridine/methicillin. Further, in MIC tests the presence of $20 \mu \mathrm{g}$ per ml of methicillin brought about an eight-fold reduction in the MIC of both ampicillin and benzylpenicillin.

E. coli 419 and E. coli $K 12 / R 7268$. These two strains were tested against 
combinations of ampicillin or cephaloridine ("protected" compounds) with methicillin or cloxacillin as the "protecting" compounds. Of the four combinations tested against each strain, all showed synergism against $E$. coli 419 , but only ampicillin/methicillin and cephaloridine/methicillin showed synergism against the R-factor-containing strain.

TABLE

Summary of the results obtained with maximum non-inhibitory concentrations (MNIC) of various $\beta$-lactam antibiotics against five bacterial strains, in paired-hole plates. $A$ combination of any compound in column 2 with any in column 3 (each at MNIC) was synergistic. No synergism was seen with any combination involving a compound in column 4. The most effective compound in each category is indicated by an asterisk

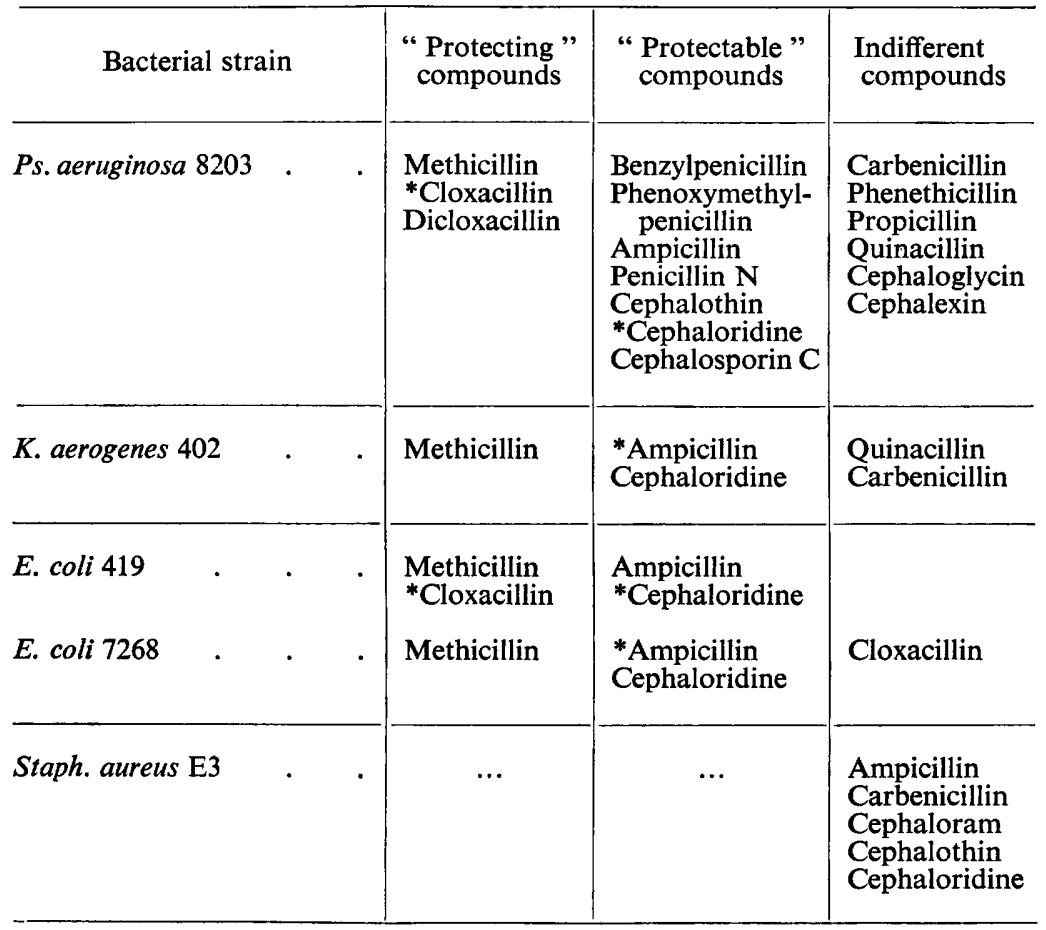

Tube tests with E. coli 419 showed that $200 \mu \mathrm{g}$ per $\mathrm{ml}$ of either methicillin or cloxacillin reduced the MIC of cephaloridine 125-fold. Plate MIC tests were carried out using as "protecting" compounds the predecessor and the successor of cloxacillin, respectively oxacillin and dicloxacillin; isobolograms constructed from the results were very similar in form to fig. 3, indicating substantial synergism.

Staph. aureus E3. With ampicillin and carbenicillin as potentially " protected" compounds, in combination with cephaloridine, cephaloram or cephalothin no synergism was observed.

The results observed in the experiments described above are summarised in the table. 


\section{Screening tests}

It is well known that $\beta$-lactam antibiotics are excreted rapidly in man, with the result that concentrations reached in the urine can be 50 times higher than peak serum levels; the choice of $1 \mathrm{mg}$ per $\mathrm{ml}$ and $20 \mu \mathrm{g}$ per $\mathrm{ml}$ as representative of the levels attainable in urine and blood respectively was an arbitrary one, based on results reported in the literature (e.g., see Lynn, 1965, for the penicillins, and Murdoch et al., 1964, Griffith and Black, 1968, and Thornhill et al., 1969, for the cephalosporins). The five antibiotics used in these tests are all clinically available.

No synergism was observed in any case in tests carried out at $20 \mu \mathrm{g} \mathrm{per} \mathrm{ml.}$ The results obtained with the antibiotics at $1 \mathrm{mg}$ per $\mathrm{ml}$ can be summarised in four groups, as follows.

$A$. No activity shown by any drug alone or in combination: Ps. aeruginosa 8203.

$B$. No activity shown by any compound alone, but some shown by certain combinations: E. cloacae strains P99 and 256, Pr. morgani strain G, Pr. vulgaris strains $\mathbf{M}$ and $\mathbf{J}$. The more active combinations against the first three strains included cloxacillin and, against the latter two strains, methicillin.

$C$. Activity shown by certain combinations at least as good as that of any single compound: Pr. morgani 185 and Pr. rettgeri 410. Cephalexin and cephaloridine alone gave small zones of inhibition against these two strains, and in both cases this activity was enhanced by combination with either methicillin or cloxacillin.

$D$. Activity shown by combinations no better than that of a single compound: K. aerogenes strains 366 and 373, E. coli strains 214T and K12/ TEM and Pr. mirabilis strains 1 and 6. For the first two strains, although synergism was observed between cephaloridine and either methicillin or cloxacillin, the resulting activity was less than that of cephalexin alone. Similarly, with $E$. coli $214 \mathrm{~T}$ the activity of both ampicillin and cephalexin was improved by the presence of cloxacillin, but the activity of cephaloridine by itself was greater than that of either of the above combinations. Under the conditions of this screen, no significant synergism was observed with E. coli K12/TEM or either of the Pr. mirabilis strains. These strains appear to be quite sensitive to cephaloridine and to cephalexin.

Thus, synergism was observed at the $1 \mathrm{mg}$ per $\mathrm{ml}$ level with ten of the 14 strains; in seven cases (strains in groups $B$ and $C$ ) the activity shown by synergistic pairs was superior to that of the most active single compound.

\section{Discussion}

The type of synergism that can be demonstrated by the technique described in this paper is of interest both from the theoretical and the laboratory point of view. These aspects will be considered in detail before a discussion of the problem of possible clinical applications of the phenomenon. 
SYNERGISM BETWEEN $\beta$-LACTAM ANTIBIOTICS

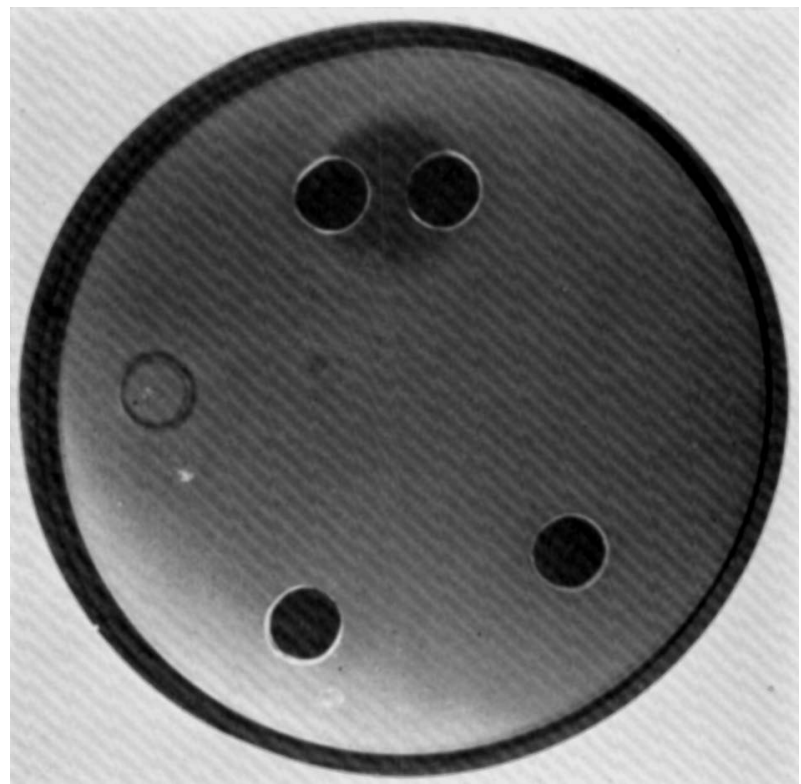

FIG. 1.-Plate showing lay-out of wells, and a positive result for synergistic activity. The left-hand wells contain $8 \mathrm{mg}$ per $\mathrm{ml}$ of cephaloridine, the right-hand wells $5 \mathrm{mg}$ per $\mathrm{ml}$ of dicloxacillin. Zone of inhibition apparent only between adjacent wells. Organism: Ps. aeruginosa NCTC 8203.

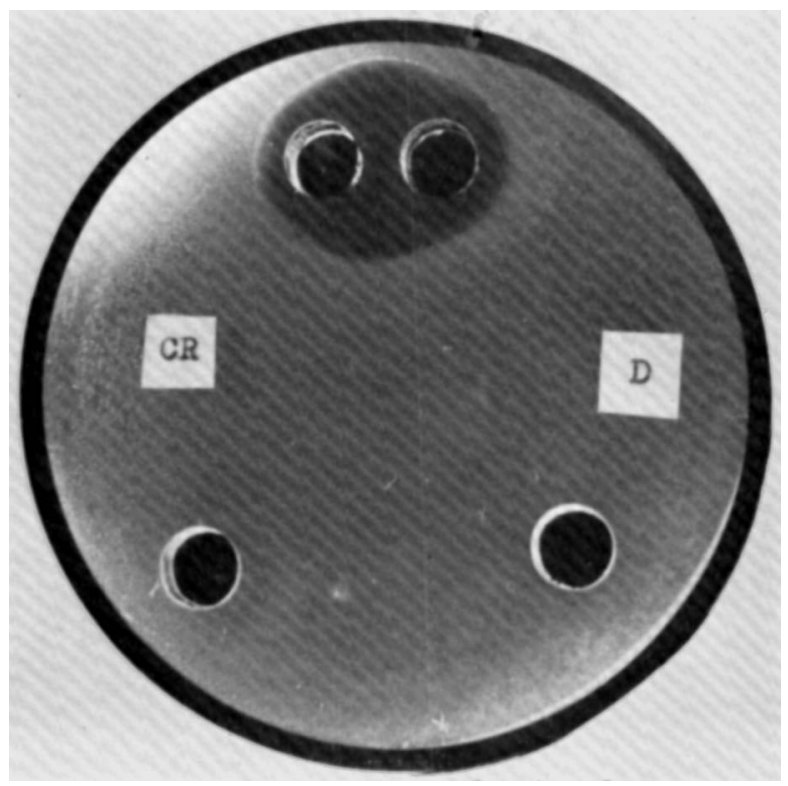

FIG. 2.-Synergism plate obtained using cephaloridine (CR) $40 \mathrm{mg}$ per $\mathrm{ml}$ and dicloxacillin (D) $20 \mathrm{mg}$ per $\mathrm{ml}$. This plate was subsequently used to test for bactericidal action by the combination (see text). 
Synergism is a much-used and much-defined word, and a great deal of controversy exists as to its true meaning, and how best it may be demonstrated (Jawetz, 1968). A merely additive effect seems to be ruled out here by the results of the isobolograms, and the fact that no zones were observed whenever one $\beta$-lactam compound was tested against itself (i.e., the same solution-at MNIC - put into all four wells of a paired-hole plate). The fact that a combination has been proved bactericidal justifies the use of the word synergism by the criteria of Elek, Hilson and Jewell (1953).

By means of the double-diffusion technique described it has been possible to show synergism between $\beta$-lactam antibiotics against all four of the Gramnegative organisms tested. Prior knowledge of certain properties of the $\beta$-lactamases involved (substrate-specificity patterns and affinity constants), although greatly decreasing the time spent in preliminary experiments, is not indispensable, as synergism tests can be carried out rapidly by the plate method once MNIC determinations have been made.

There are three general criteria for synergism to occur between two $\beta$ lactam compounds $\mathrm{X}$ and $\mathrm{Y}$ acting against a certain bacterial strain.

1. The strain must produce $\beta$-lactamase.

2. X must be hydrolysable, i.e., the organism must show a " $\beta$-lactamasetype " resistance to $X$ by itself.

3. $Y$ must be a stable competitive inhibitor of the $\beta$-lactamase under physiological conditions (i.e., in the presence of whole bacterial cells).

When two $\beta$-lactam antibiotics fulfil these conditions, synergism will occur; in order for this synergism to be detectable by the paired-hole technique, a fourth condition must be added.

4. $Y$ must be capable of maintaining the concentration of $X$ above its MIC for sufficient time for a bactericidal effect to take place.

Thus, in general, the higher the degree of competitive inhibition, the greater will be the synergistic effect, and the more likely that it will be of sufficient magnitude to be detectable. Two main factors affect this degree of inhibition, namely the relative affinities of $\mathrm{Y}$ and $\mathrm{X}$ for the $\beta$-lactamase, and their relative concentrations. A detailed mathematical treatment of the enzyme kinetics involved appears elsewhere (Hamilton-Miller, 1971).

It is of some interest to analyse the failure to observe synergism against Staphylococcus aureus E3 in terms of the above considerations, taking the pair ampicillin/cephalothin as an example; the organism, ampicillin and cephalothin fulfilled criteria 1,2 and 3 . The ratio of the affinities of ampicillin and cephalothin for Staph. aureus E3 penicillinase is $4.3 \times 10^{-4}$ (Hamilton-Miller, 1970) which is comparable to the value $\left(1.7 \times 10^{-4}\right)$ for the cephalosporin $\mathrm{C} /$ methicillin combination, which shows marked synergistic activity against Pseudomonas aeruginosa 8203 (Sabath et al., 1965). Hence it seems likely that the failure of ampicillin/cephalothin to be effective against Staph. aureus E3 lies in the ratio of their concentrations, which is $2.8 \times 10^{-3}$ here, compared with 0.16 for the 
cephalosporin $\mathrm{C} /$ methicillin combination mentioned above. In these experiments, by their very nature, the concentration of the inhibitor cannot exceed MNIC, which in the case of cephalothin and Staph. aureus is extremely low. Could one find a cephalosporin with low intrinsic activity (and hence a high MNIC) combined with high affinity for staphylococcal $\beta$-lactamase, doubtless a synergistic pair could be made between ampicillin and this compound. Synergism has in fact been observed (Hamilton-Miller, 1970) between ampicillin and cephalothin against Staph. aureus E3, but only in short-term (8-hr) growth experiments. Crawford and Abraham (1957) reported synergism between cephalosporin C and benzylpenicillin against Staph. aureus D3R, a finding that was confirmed by Jago (1964). However, as cephaloram did not act synergistically with benzylpenicillin against this strain, it may be that synergism in this case was not due to inhibition of $\beta$-lactamase activity (see Crompton et al., 1962).

In the course of MNIC determinations with Ps. aeruginosa 8203, it was noted that carbenicillin was ten times more active than the next best compound, and that this organism showed no sign of " $\beta$-lactamase-type " resistance to carbenicillin. The observation that N-benzoyl penicillin N, whose MNIC was at least four times greater than that of penicillin N, lacked activity against this strain was of interest in view of the recent reports that semisynthetic penicillins with a free acidic group in their side-chain have enhanced antipseudomonadal activity (Acred et al., 1967; Price et al., 1969; Essery, 1969). The above observation suggests that the acid group must be on the $\alpha$-carbon atom in the side-chain for this type of activity to be shown.

The results of the screening tests show that, in certain cases, an appropriate synergistic pair may show greater activity against a bacterial strain than does any single compound. This situation obtained for half of the 14 strains screened here. If such a strain were the causal organism of an infection of the urinary tract, it might be justifiable, on bacteriological grounds, to suggest treatment with two $\beta$-lactam antibiotics (combined therapy). It is important, however, that before such a recommendation be made, the actual strain is isolated from the patient and synergism demonstrated with it in vitro. Irrational or random use of combined therapy will inevitably give rise to a high incidence of failure, which will result in the treatment falling into disrepute. Such a fate would be unfortunate, as it seems that, in certain types of case (Sabath et al., 1967a and $b$; Maddocks and May, 1969), such combined therapy may be advantageous. Clearly, the necessary preliminary screening tests require time-possibly 2 or 3 days from the isolation of the organism-but in the cases that seem likely to merit this kind of treatment (e.g., chronic bacilluria) time is not of the essence.

An aspect of the problem to which little or no notice has been given is the question of the metabolism of $\beta$-lactam drugs in vivo. It is well established that certain penicillins (Rolinson and Batchelor, 1963) are excreted in the urine partly in the form of metabolites, and that some cephalosporins (O'Callaghan and Muggleton, 1963) are deacetylated in vivo. Thus, if cephalothin or cephaloglycin are contemplated as members of synergistic pairs to be used therapeutically, it must be borne in mind that these compounds will exist in the urine 
largely as the less biologically active deacetyl analogues (Sullivan and McMahon, 1967; Sullivan, Billings and McMahon, 1969a); hence, the deacetyl rather than the parent compounds should be used for the preliminary in-vitro tests. However, it is known that, of the five compounds used here for screening experiments, three-ampicillin, methicillin (Rolinson and Batchelor) and cephalexin (Sullivan, Billings and McMahon, 1969b) - are excreted unchanged, whilst cloxacillin (Rolinson and Batchelor) and cephaloridine (Stewart and Holt, 1964) are metabolised in vivo only to a very limited extent. Thus, the results obtained in the screening tests described here are applicable to in-vivo situations.

\section{SUMMARY}

Synergism has been demonstrated between selected pairs of $\beta$-lactam antibiotics against four representative strains of $\beta$-lactamase-producing Gramnegative bacteria (Pseudomonas aeruginosa, Escherichia coli, Klebsiella aerogenes and an R-factor-bearing $E$. coli strain). A pour-plate double-diffusion technique with subinhibitory concentrations of antibiotics was used. Synergism has been proven by demonstrating a bactericidal effect, and by the isobologram technique. Seven out of 14 highly resistant strains of Gram-negative bacteria proved to be more sensitive to certain combinations of $\beta$-lactam antibiotics than to any of these antibiotics alone, tested at $1 \mathrm{mg}$ per $\mathrm{ml}$ (a concentration attainable in the urine during therapy). Some aspects of the possible clinical use of combined therapy with two $\beta$-lactam antibiotics are discussed.

Some of this work was carried out during the tenure of a Medical Research Council Junior Research Fellowship. I am indebted to Professor E. P. Abraham for his encouragement and for reading the manuscript, and to Dr N. G. Heatley for help in drafting. I gratefully acknowledge the skilled assistance of Miss A. L. Fairbairn and Mrs J. Benson (Miss A. Giles), and thank the Medical Research Council and National Research Development Corporation for financial assistance.

\section{REFERENCES}

Abraham, E. P., AND Newton, G. G. F. 1956. Experiments on the degradation of cephalosporin C. Biochem. J., 62, 658.

Abraham, E. P., Newton, G. G. F., and Hale, C. W. 1954. Purification and some properties of cephalosporin N, a new penicillin. Biochem. J., 58, 94.

ACred, P., Brown, D. M., Knudsen, E. T., Rolinson, G. N., and Sutherland, R. 1967. New semi-synthetic penicillin active against Pseudomonas pyocyanea. Nature, Lond., 215, 25.

Brownlee, K. A., Delves, C. S., Dorman, M., Green, C. A., Grenfell, E., Johnson, J. D. A., AND SMITH, N. 1948. The biological assay of streptomycin by a modified cylinder plate method. J. Gen. Microbiol., 2, 40.

Crawford, Kathleen, AND Abraham, E. P. 1957. The synergistic action of cephalosporin C and benzylpenicillin against a penicillinase-producing strain of Staphylococcus aureus. J. Gen. Microbiol., 16, 604.

Crompton, Brenda, Jago, Margaret, Crawford, Kathleen, Newton, G. G. F., and AbrahAM, E. P. 1962. Behaviour of some derivatives of 7-aminocephalosporanic acid and 6-aminopenicillanic acid as substrates, inhibitors and inducers of penicillinases. Biochem. J., 83, 52. 
Datta, Naomi, and Kontomichalou, Polyxeni 1965. Penicillinase synthesis controlled by infectious $R$ factors in Enterobacteriaceae. Nature, Lond., 208, 239.

Elek, S. D., Hilson, G. R. F., AND Jewell, Pamela 1953. Laboratory aspects of combined antibiotic treatment. Br. Med. J., 2, 1298.

ESSERY, J. M. 1969. Preparation and antibacterial activity of $\alpha$-(5-tetrazolyl)benzylpenicillin. J. Mednl Chem., 12, 703.

Griffith, R. S., AND BlaCK, H. R. 1968. Cephalexin: a new antibiotic. Clin. Med., 75 , no. 11 , p. 14.

Hamilton-Miller, J. M. T. 1967. Hydrolysis of cephalosporins by $\beta$-lactamases from Gram-negative bacteria. Nature, Lond., 214, 1333.

HAMilton-MilleR, J. M. T. 1968. Wild type variants of penicillinase from Klebsiella aerogenes. FEBS Lett., $1,86$.

HAmilton-Miller, J. M. T. 1970. A comparison of the penicillinases from a methicillinsensitive and from a methicillin-resistant stain of Staphylococcus aureus. Guy's Hosp. Rep., 119, 155.

Hamlton-Miller, J. M. T. 1971. Use of Michaelis-Menten kinetics in the analysis of synergism between $\beta$-lactam antibiotics. J. Theor. Biol., 31, 171.

Hamilton-Miller, J. M. T., Smith, J. T., AND Knox, R. 1964. Potentiation of penicillin activity by inhibition of penicillinase. Nature, Lond., 201, 867.

Hamilton-MilleR, J. M. T., Smith, J. T., AND KNOX, R. 1965. Interaction of cephaloridine with penicillinase-producing Gram-negative bacteria. Nature, Lond., 208, 235.

Hennessey, T. D. 1967. Inducible $\beta$-lactamase in Enterobacter. J. Gen. Microbiol., 49, 277.

JAGo, MARgaret 1964. Antibacterial activity of some derivatives of 7-aminocephalosporanic acid against Staphylococcus aureus and synergism between these and other antibiotics. Br. J. Pharmac. Chemother., 22, 22.

JAwETZ, E. 1968. The use of combinations of antimicrobial drugs. A. Rev. Pharmac., $8,151$.

Knox, R. 1960. A new penicillin (BRL 1241) active against penicillin-resistant staphylococci. Br. Med. J., 2, 690.

Loder, Bronwen, Newton, G. G. F., and Abraham, E. P. 1961. The cephalosporin C nucleus (7-aminocephalosporanic acid), and some of its derivatives. Biochem. J., 79, 408.

LYNN, B. 1965. The semi-synthetic penicillins. Antibiotica Chemother., 13, 125.

MADDOCKS, J. L., AND MAY, J. R. 1969. "Indirect pathogenicity " of penicillinase-producing enterobacteria in chronic bronchial infections. Lancet, 1, 793.

Meynell, Elinor, and DAtTa, NAOMI 1966. The relation of resistance transfer factors to the F-factor (sex-factor) of Escherichia coli K12. Genet. Res., 7, 134.

Murdoch, J. McC., Speirs, C. F., Geddes, A. M., and Wallace, E. T. 1964 . Clinical trial of cephaloridine (Ceporin), a new broad-spectrum antibiotic derived from cephalosporin C. Br. Med. J., 2, 1238.

Newton, G. G. F., AND Abraham, E. P. 1954. Degradation, structure and some derivatives of cephalosporin N. Biochem. J., 58, 103.

O'Callaghan, Cynthia H., and Muggleton, P. W. 1963. The formation of metabolites from cephalosporin compounds. Biochem. J., 89, 304.

Price, K. E., Chisholm, D. R., Leitner, F., Misiek, M., ANd Gourevitch, A. 1969. Antipseudomonal activity of $\alpha$-sulfoaminopenicillins. Appl. Microbiol., 17, 881 .

Rolinson, G. N., AND Batchelor, F. R. 1963. Penicillin metabolites. Antimicrobial agents and chemotherapy, 1962, ed. by J. C. Sylvester, Ann Arbor, p. 654.

SABATH, L. D. 1968. Synergy of antibacterial compounds by apparently known mechanisms. Antimicrobial agents and chemotherapy, 1967, ed. by Gladys L. Hobby, Ann Arbor, p. 210.

Sabath, L. D., AND Abraham, E. P. 1964. Synergistic action of penicillins and cephalosporins against Pseudomon - pyocyanea. Nature, Lond., 204, 1066.

Sabath, L. D., Elder, H. A., McCall, C. E., and Finland, M. 1967a. Synergistic combinations of penicillins in the treatment of bacteriuria. New Engl. J. Med., 277, 232. 
Sabath, L. D., Jago, Margaret, and Abraham, E. P. 1965. Cephalosporinase and penicillinase activities of a $\beta$-lactamase from Pseudomonas pyocyanea. Biochem. J., 96, 739.

Sabath, L. D., McCall, C. E., Steigbigel, N. H., and Finland, M. 1967b. Synergistic penicillin combinations for treatment of human urinary-tract infections. Antimicrobial agents and chemotherapy, 1966, ed. by Gladys L. Hobby, Ann Arbor, p. 149.

Smith, J. T. 1963. Penicillinase and ampicillin resistance in a strain of Escherichia coli. J. Gen. Microbiol., 30, 299.

Smith, J. T., AND Hamilton-Miller, J. M. T. 1963. Differences between penicillinases from Gram-positive and Gram-negative bacteria. Nature, Lond., 197, 976.

Smith, J. T., Hamilton-Miller, J. M. T., AND KNox, R. 1969. Bacterial resistance to penicillins and cephalosporins. J. Pharm. Pharmac., 21, 337.

Stewart, G. T., AND Holt, R. J. 1964. Laboratory and clinical results with cephaloridine. Lancet, 2, 1305.

Sullivan, H. R., Billings, Ruth E., AND McMahon, R. E. 1969a. Metabolism of Dcephaloglycin-14C and L-cephaloglycin-14C in the rat. J. Antibiot., Tokyo, 22, 27.

Sullivan, H. R., Billings, Ruth E., AND McMahon, R. E. 1969 $\mathrm{b}$. Metabolism of cephalexin-14C in mice and in rats. J. Antibiot., Tokyo, 22, 195.

Sullivan, H. R., AND MCMAHON, R. E. 1967. Metabolism of oral cephalothin and related cephalosporins in the rat. Biochem. J., 102, 976.

Sutherland, R., AND BATCHELOR, F. R. 1964. Synergistic activity of penicillins against penicillinase-producing Gram-negative bacilli. Nature, Lond., 201, 868.

Thornhill, T. S., Levison, M. E., Johnson, W. D., AND KAYE, D. 1969. In vitro antimicrobial activity and human pharmacology of cephalexin, a new orally absorbed cephalosporin C antibiotic. Appl. Microbiol., 17, 457. 